\title{
MATERNAL MORTALITY- A DECADE'S EXPERIENCE IN A TERTIARY CARE CENTRE IN JHARKHAND
}

\author{
Tubid Rajluxmi ${ }^{1}$
}

${ }_{1}^{1}$ Associate Professor, Department of Obstetrics and Gynaecology, Patliputra Medical College, Dhanbad, Jharkhand, India.

\section{ABSTRACT}

\section{BACKGROUND}

Maternal death has a huge impact on the family, society and the nation. The aim of this study was to calculate the Maternal Mortality Ratio over a period of ten years, to study the main causes and epidemiological factors of maternal death and identify areas needing targeted intervention to achieve the Millennium Development Goal-5 (MDG-5) of reducing Maternal Mortality Ratio (MMR) by three-quarters.

\section{MATERIALS AND METHODS}

A 10 years retrospective descriptive study of hospital records from January 2007 to December 2016 was carried out. The MMR was computed, epidemiological data was analysed, and cause of death studied.

\section{RESULTS}

There were 34,187 live births with 278 maternal deaths during the study period. The cumulative MMR was 813 per 100,000 live births. Majority $64.7 \%$ of maternal deaths occurred in the age group of 21 - 30 years, $71.9 \%$ were from rural area, $62.9 \%$ belonged to low socioeconomic strata and $54.3 \%$ were in multigravida. There were $76 \%$ unbooked pregnancies and $23 \%$ were referred cases. Vast majority $67.9 \%$ died undelivered and $66.18 \%$ died within 24 hours of admission. Major causes of maternal deaths included eclampsia in $42.8 \%$, anaemia in $26.6 \%$ and haemorrhage in $19.06 \%$.

\section{CONCLUSION}

Eclampsia, anaemia and haemorrhage are the major killers. Quality antenatal care, early identification of high-risk pregnancies, early referral, early identification of anaemia during pregnancy and iron supplementation along with proper referral of eclamptic patients will go a long way in reducing maternal mortality. There should be a dedicated HDU and ICU for obstetric cases in tertiary care centres along with availability of blood components in blood banks attached to these centres for dealing with massive obstetric haemorrhage.

\section{KEY WORDS}

Maternal Death, Maternal Mortality Ratio, MDG-5, MMR, Jharkhand, Causes of Maternal Mortality.

HOW TO CITE THIS ARTICLE: Rajluxmi T. Maternal mortality- a decade's experience in a tertiary care centre in Jharkhand. J. Evolution Med. Dent. Sci. 2018;7(23):2742-2745, DOI: 10.14260/jemds/2018/619

\section{BACKGROUND}

Maternal mortality is a sentinel event to assess the quality of health care services, its utilisation and its delivery. It causes a huge loss of human life and is a reflection of social welfare schemes, hence it is the mirror of health of a nation. According to the World Health Organisation (WHO), maternal death is defined as "death of a woman while pregnant or within 42 days of termination of pregnancy, irrespective of the duration and site of pregnancy from any cause related to or aggravated by the pregnancy or its management, but not from accidental or incidental causes."[1]

Maternal Mortality Ratio (MMR) is defined as the number of maternal deaths during a given period per 100,000 live births during the same period.[1] Most of the maternal deaths continue to be associated with determinants such as malnutrition, parity, socioeconomic marginalisation over which policies have had little or no impact.[2]

'Financial or Other Competing Interest': None.

Submission 23-04-2018, Peer Review 19-05-2018,

Acceptance 25-05-2018, Published 04-06-2018.

Corresponding Author:

Tubid Rajluxmi

Department of Obstetrics and Gynaecology,

Patliputra Medical College, Saraidhela,

Dhanbad-833205,

Jharkhand.

E-mail: dr.rajluxmi@gmail.com

DOI: $10.14260 /$ jemds $/ 2018 / 619$

\section{(c) $($ i) $\risingdotseq$}

Under the International Statistical Classification of Diseases and related health problems, $10^{\text {th }}$ Revision (ICD-10) the causes of maternal deaths are classified broadly as "direct" and "indirect." Direct causes include deaths resulting from obstetrical complications of the pregnant state (Pregnancy, delivery and postpartum), interventions, omissions, incorrect treatment or a chain of events resulting from any of the above. Indirect causes are deaths occurring from previously existing diseases or from diseases that developed during pregnancy and were not due to direct obstetric causes, but were aggravated by the physiological effects of pregnancy.[2]

MMR in India was 174 (RGI-2015) according to World Bank data.[3] High maternal mortality in India, particularly across Empowered Action Group (EAG) States is a critical policy concern. ${ }^{[2]}$ Jharkhand is one of the EAG states along with Uttar Pradesh, Madhya Pradesh, Chhattisgarh, Bihar, Rajasthan and Orissa. MMR of Jharkhand has declined from 278 in 2010 - 2011 to 245 in the Year 2012 - 2013.[4]

This study was undertaken to compute the Maternal Mortality Ratio in a tertiary care centre of Jharkhand to analyse the socioeconomic and demographic profile, study the causes of death and identify possible remedial measures to reduce the MMR.

\section{MATERIALS AND METHODS}

Study Design: This is a retrospective descriptive study, conducted in the Department of Obstetrics and Gynaecology, 
Patliputra Medical College and Hospital, Dhanbad, Jharkhand. All maternal deaths from January 2007 to 2016 were reviewed. Hospital records and patient case sheets were studied.

\section{The Maternal Mortality Ratio (MMR) was calculated by the Formula}

MMR $=\frac{\text { Total Maternal Death (in a given period) }}{\text { Total Live Births (in the same period) }} \times 100,000$

Maternal death with respect to variables like age, parity, area of residence, socioeconomic status, admission-death interval and cause of death were reviewed. As per definition of maternal deaths (WHO) due to accident or suicide were excluded.

Statistical Analysis: Appropriate descriptive statistics tools like number (n), proportion and percentages (\%) were used to analyse the data.

\section{RESULTS}

There were 34,187 live births from January 2007 to December 2016 and 278 maternal deaths. The MMR was 813 per 100,000 live births. There has been a gradual decline in MMR from 1243 in the year 2007 to 717 in the year 2016 as shown in Table 1. The comparative MMR in the first half of the study period (2007 - 2011) and that in the second half (2012 - 2016) has been shown in Table 2. The MMR between the periods 2007 to 2011 was 1074, which fell to 662 in the period 2012 to 2016 which depicts that there has been a marked decline in MMR.

The data of total 278 maternal deaths during the study period has been analysed. Table 3 shows the epidemiological characteristics of maternal deaths. Majority of the maternal deaths occurred in women from rural areas $(71.9 \%)$ with low socioeconomic status $(62.9 \%)$. More than $3 / 4^{\text {th }}$ of maternal deaths occurred in unbooked cases $(75.8 \%)$. There were $23.02 \%$ referred patients. A vast majority $(64.7 \%)$ of maternal death occurred in the age group of 21 - 30 years and in multiparous women (54.3\%).

Table 4 shows the admission death interval. Maximum mortality occurred within 24 hours of admission (66.18\%), $17.2 \%$ died between $25-48$ hours, whereas only $6.8 \%$ of deaths occurred beyond 72 hours.

Over $2 / 3^{\text {rd }}(67.9 \%)$ maternal deaths occurred in undelivered cases. Postpartum deaths accounted for $29.13 \%$ of maternal deaths and $2.87 \%$ were abortion related deaths.

Cause of death has been shown in Table 5. Of the total of 278 mortalities, there were 185 (66.54\%) deaths due to direct causes and 93 (33.46\%) deaths could be ascribed to indirect causes. Amongst the direct causes, maximum deaths were due to eclampsia in 119 (42.8\%) followed by haemorrhage in $53(19.06 \%)$ and sepsis in 13 (4.67\%). Amongst indirect causes, anaemia was responsible in 74 $(26.6 \%)$ followed by heart disease in $8(2.87 \%)$ and hepatic disorders in $4(1.43 \%)$ patients. Sudden maternal collapse occurred in $4(1.43 \%)$ patients and $3(1.07 \%)$ deaths were due to complicated malaria.
Of the 53 deaths due to haemorrhage there were 18 cases of ruptured uterus, 18 cases of postpartum haemorrhage, 10 cases of antepartum haemorrhage and 7 cases of retained placenta. There were 8 cases of post abortal sepsis and 5 cases of postpartum sepsis.

Table 6 shows the comparative analysis between various studies. Our study has shown greater incidence of deaths due to pre-eclampsia/ eclampsia and anaemia followed by haemorrhage and sepsis.

\begin{tabular}{|c|c|c|c|}
\hline Year & Live Births & $\begin{array}{c}\text { Maternal } \\
\text { Death }\end{array}$ & MMR \\
\hline 2007 & 2010 & 25 & 1243 \\
2008 & 2004 & 28 & 1397 \\
2009 & 2458 & 29 & 1180 \\
2010 & 2881 & 27 & 937 \\
2011 & 3220 & 26 & 807 \\
2012 & 3726 & 28 & 751 \\
2013 & 4112 & 27 & 656 \\
2014 & 4770 & 27 & 574 \\
2015 & 3986 & 25 & 627 \\
2016 & 5020 & 36 & 717 \\
\hline Total & 34187 & $\mathbf{2 7 8}$ & $\mathbf{8 1 3}$ \\
\hline \multicolumn{4}{|c|}{ Table 1. Year-Wise Maternal Mortality Ratios } \\
\hline
\end{tabular}

\begin{tabular}{|c|c|c|c|}
\hline Year & Live Births & $\begin{array}{c}\text { Maternal } \\
\text { Death }\end{array}$ & MMR \\
\hline $2007-2011$ & 12573 & 135 & 1074 \\
\hline $2012-2016$ & 21614 & 143 & 662 \\
\hline Total & $\mathbf{3 4 1 8 7}$ & $\mathbf{2 7 8}$ & \\
\hline \multicolumn{4}{|l}{ Table 2. Comparative MMR between 2007-11 and 2012-16 } \\
\hline
\end{tabular}

\begin{tabular}{|c|c|c|c|}
\hline & & No. (n= 278) & Percentage (\%) \\
\hline Age (Years) & & 60 & 21.58 \\
\hline & $<20$ & 180 & 64.74 \\
\hline & $21-30$ & 38 & 13.66 \\
\hline & $>30$ & \multicolumn{3}{|c|}{ Parity } \\
\hline & Primigravida & 127 & 45.68 \\
\hline & Multigravida & 151 & 54.31 \\
\hline \multicolumn{4}{|c|}{ Area of Residence } \\
\hline & Rural & 200 & 71.94 \\
\hline & Urban & 78 & 28.05 \\
\hline \multicolumn{4}{|c|}{ Socioeconomic Strata } \\
\hline & Low & 175 & 62.94 \\
\hline & Middle & 103 & 37.05 \\
\hline \multicolumn{3}{|c|}{ Status } \\
\hline Parity, Area of Residence, Socioeconomic Strata and Status \\
at Admission \\
\hline
\end{tabular}

\begin{tabular}{|c|c|c|}
\hline Time (Hours) & No. (n= 278) & Percentage (\%) \\
\hline$<24$ & 184 & 66.18 \\
\hline $25-48$ & 48 & 17.26 \\
\hline $49-72$ & 27 & 09.71 \\
\hline$>72$ & 19 & 6.83 \\
\hline \multicolumn{2}{|c|}{ Table 4. Admission Death Interval } \\
\hline
\end{tabular}




\begin{tabular}{|c|c|c|c|c|c|c|}
\hline & No. $(n=278)$ & No. & No. & Percent & Percent & Percent \\
\hline Direct & 185 & & & & & 66.54 \\
\hline 1. Eclampsia & & 119 & & & 42.80 & \\
\hline \multirow[t]{3}{*}{ 2. Haemorrhage } & 1. $\quad$ Rupture uterus & 53 & 18 & 33.96 & 19.06 & \\
\hline & 2. Postpartum haemorrhage & & 18 & 33.96 & & \\
\hline & $\begin{array}{l}\text { 3. Antepartum haemorrhage } \\
\text { 4. Retained placenta }\end{array}$ & & $\begin{array}{l}10 \\
07\end{array}$ & $\begin{array}{l}18.86 \\
13.20 \\
\end{array}$ & & \\
\hline 3. Sepsis & $\begin{array}{l}\text { 1. Puerperal sepsis } \\
\text { 2. Post abortal }\end{array}$ & 13 & $\begin{array}{l}05 \\
08\end{array}$ & $\begin{array}{l}38.46 \\
61.53\end{array}$ & 4.67 & \\
\hline \begin{tabular}{l}
\multicolumn{1}{c}{ Indirect } \\
1. Anaemia \\
2. Heart disease \\
3. Sudden death \\
4. Hepatic disorder \\
5. Malaria \\
\end{tabular} & 93 & $\begin{array}{l}74 \\
08 \\
04 \\
04 \\
03\end{array}$ & & & $\begin{array}{c}26.61 \\
2.87 \\
1.43 \\
1.43 \\
1.07 \\
\end{array}$ & 33.45 \\
\hline \multicolumn{7}{|c|}{ Table 5. Causes of Maternal Deaths } \\
\hline
\end{tabular}

\begin{tabular}{|c|c|c|c|c|c|c|c|c|}
\hline Study & Year & MMR & $\begin{array}{c}\text { Direct } \\
\text { Causes }\end{array}$ & $\begin{array}{c}\text { Indirect } \\
\text { Causes }\end{array}$ & E/PE* & Haemorrhage & Sepsis & Anaemia \\
\hline Bhaskar K Murthy et al & $2001-10$ & 302.3 & $72.5 \%$ & $27.5 \%$ & $26.66 \%$ & $26.66 \%$ & $18.33 \%$ & $10 \%$ \\
\hline Konar Hiralal et al & $2005-07$ & 596.2 & - & - & $29.54 \%$ & $21.56 \%$ & - & $11.69 \%$ \\
\hline Biswajit Paul et al & $2006-07$ & 727 & $76.7 \%$ & - & $32.6 \%$ & $14 \%$ & $14 \%$ & $48.3 \%$ \\
\hline Malipatil P & $2007-12$ & 586 & - & - & $10 \%$ & $36 \%$ & $16.1 \%$ & $8 \%$ \\
\hline Khandale SN et al & $2011-15$ & - & $61.51 \%$ & $39.1 \%$ & $28.19 \%$ & $10.25 \%$ & $14.10 \%$ \\
\hline Urmila Mahala et al & $2007-16$ & 253.1 & $66.95 \%$ & $33.04 \%$ & $22.4 \%$ & $33.89 \%$ & $8 \%$ & $17.52 \%$ \\
\hline Our Study & $2007-16$ & 813 & $66.54 \%$ & $33.46 \%$ & $42.8 \%$ & $19.06 \%$ & $4.67 \%$ & $26.6 \%$ \\
\hline \multicolumn{78}{|c|}{ Table 6. Comparative Analysis of Various Studies } \\
\hline
\end{tabular}

*E/ PE: eclampsia/ preeclampsia.

\section{DISCUSSION}

There has been a steady decline in the Maternal Mortality Ratio over the 10-year study period in our institution. On comparing the first five years of the study period 2007 to 2011 to the next half 2012 to 2016, the MMR fell from 1074 to 662. With the National Rural Health Mission (NRHM) and Safe Motherhood Programme complemented by the Janani Shishu Suraksha Yojna (JSSY), in which financial incentives and logistical supports were intensified. The effort has yielded encouraging results. Comparing this with other institutional figures (Table 6), national MMR (167) and other states our figures are high and there is a lot of scope for improvement. One of the many reasons could be that this institution covers areas, which have difficult terrain and most of the cases come from far flung interior rural inaccessible areas where means of commuting are not easily available. Patients from these areas have to face difficulties in transportation. The literacy rates are poor in this area with lack of awareness regarding health facilities available to them. In addition to above factors, there are deep rooted faith in traditional system of treatment. The study by Urmila Mahala et al[4] has shown an MMR of 253.15 during the same period. Majority of our patients were from rural area $71.9 \%$. Similar figures have been quoted by Urmila Mahala 74.1\%,[4] Khandale SN 69.23\%,[5] Malipatil P 69\%[6] and Bhaskar K Murthy $69.16 \% .{ }^{[7]}$ In our study, low socio-economic status was associated $62.9 \%$ with the high MMR. Similar rates have been reported by Biswajit Paul $60.5 \%{ }^{[8]}$ and U Mahala $78.7 \% .{ }^{[4]}$ In our study, majority of the deaths have taken place in the 21 to 30 years' age group, a phenomenon which was also seen in the studies by $\mathrm{V}$ Ashok $78.5 \%$,[9] Bhaskar $\mathrm{K}$
Murthy 70\%[7] and Biswajit Paul 72.1\%.[8] Our study showed more deaths amongst multigravidas $54.3 \%$, which is similar to the studies by U Mahala $60.9 \%,{ }^{[4]}$ Bhaskar K Murthy 56.65\%[7] and Malipatil P 64\%.[6] We had 75.8\% unbooked cases. Similar percentages were seen in the studies by $\mathrm{U}$ Mahala $88.79 \%\left[{ }^{[4]}\right.$ and Bhaskar K Murthy 83.33\%.[7] Hence, this study reiterates the finding that young mothers, multigravidas, from low socioeconomic strata and those with none or inadequate antenatal care are dying more. All these are preventable factors.

In our study, majority of casualties occurred within 24 hours of admission. Studies by Pratima D[10] and Malipatil D[6] have shown similar observation. The reason behind this high majority within 24 hours of hospitalisation are late referrals from far flung areas, patients being in moribund condition in whom all resuscitative efforts fail. Majority of our patients died undelivered, $67.9 \%$. As compared to other studies, our figures are higher because we have very high percentage of patients with eclampsia and anaemia, majority of whom were received in critical states and died within 24 hours of admission. Direct causes were accountable for in $66.54 \%$ of the deaths with eclampsia leading the list to $42.8 \%$, anaemia $26.6 \%$ and haemorrhage $19.05 \%$ following close behind Studies by Khandale $\mathrm{SN}^{*}[5]$ had direct causes in $61.51 \%$, Urmila M 66.95\%,[4] Biswajit Paul 76.7\%[8] and Bhaskar K Murthy $72.5 \% .{ }^{[7]}$ This study has shown an alarmingly high incidence for eclampsia deaths in comparison to other studies as shown in Table 5. Majority of eclamptic deaths have occurred within 24 hours and had multiorgan failure. The standard protocol of eclampsia management by magnesium sulphate injections laid down by WHO was not followed.[11] Majority of the eclamptic patients had 10 to 15 fits before 
arrival at this institute. For deaths due to anaemia, majority died undelivered because they were in decompensated state. Majority of anaemic patients had not undergone any antenatal check-ups and had not received the mandatory iron and folic acid supplementation. Deaths due to eclampsia and anaemia was also high in study by Biswajeet Paul from Odisha[8] and FOGSI Study by Hiralal Konar.[12] Obstetric haemorrhage particularly due to rupture uterus was seen in significant number of patients with previous operative deliveries as a result of injudicious conduct of labour in previous cases who had a history of caesarean sections. Puerperal sepsis has shown a decline because of increasing institutional deliveries. However, incidence of post abortal sepsis related deaths have remained the same. Most of the abortion related deaths had unsafe illegal abortions by unskilled personnel resulting in visceral injuries.

\section{CONCLUSION}

The maternal mortality rates are gradually decreasing, but more focused interventions are required. Hypertensive disorders of pregnancy including eclampsia has remained the leading cause of maternal death requiring intensified action including early diagnosis and referral, along with the use of magnesium sulphate and encouraging eclampsia drill for all health care providers right from peripheral to tertiary centres. Obstetric haemorrhage, particularly rupture uterus in previous operative deliveries calls for re-emphasising on the dictum- "previous caesarean always an institutional delivery." The practice of unsafe abortions is still continuing. Safe abortion services by skilled providers have to be accessible to all. More emphasis on contraceptive practices to avoid unwanted pregnancies will help prevent abortion related deaths. Quality antenatal care and strict vigilance for identifying high-risk pregnancies like pre-eclampsia and anaemia will go a long way in reducing maternal mortality. Increasing health awareness programs and removing prejudices and wrong practices which are deep rooted amongst the rural population of this area will also help ameliorate the scourge of preventable maternal deaths. The existing peripheral health care establishments and health care providers need to be upgraded in terms of infrastructure, knowledge and skill for safe delivery practices. Encouraging blood donation so that the community is a stakeholder in the Safe Motherhood Programme plays its role and will help in meeting the demand for blood in cases of obstetric haemorrhage adequately. The tertiary centres like medical colleges should have separate obstetric HDU, ICU for obstetric wing with dedicated staffing to be able to provide critical care.

\section{REFERENCES}

[1] Park. Preventive medicine in obstetrics, pediatrics, and geriatrics. Park's Textbook of preventive and social medicine. 23rd edn. Bhanot Publisher 2015; p. 557-60.

[2] Joe W, Sharma S, Sharma J, et al. Maternal mortality in India: a review of trends and patterns. IEG Working Paper No, 353, 2015; p. 21.

[3] Indian Maternal Mortality Rate Source: CIA World Fact book - last updated Jan 20, 2018. https://www. Indexmundi.com

[4] Mahala U, Prakash O, Mehta S, et al. Maternal mortality at tertiary care hospital in Rajasthan: a 10 - year review. IOSR Journal of Dental and Medical Sciences (IOSR-JDMS) 2017;16(6):89-92.

[5] Khandale SN, Kedar K. Analysis of maternal mortality: a retrospective study at tertiary care centre. Int J Reprod Contraception Obstet Gynecol 2017;6(4):1610-3.

[6] Malipatil P, Chaitanya VM. Maternal mortality at a government teaching hospital: a six year duration study. Int J Reprod Contracep Obstet Gynecol 2016;5(3):890-3.

[7] Murthy BK, Murthy MB, Prabhu PM. Maternal mortality in a tertiary care hosp: a 10 year review. Int J Prev Med 2013;4(1):105-9.

[8] Paul B, Mohapatra B, Kar K. Maternal deaths in a tertiary health care centre of Odisha: an in-depth study supplemented by Verbal Autopsy. Indian J Community Med 2011;36(3):213-6.

[9] Ashok V, Santosh M, Anupa S. A study on maternal mortality. J Obstet \& Gynecol India 2008;58(3):226-9.

[10] Khumanthem PD, Chanam MS, Samjetshabam RD. Maternal mortality and its causes in a tertiary center. J Obstet \& Gynecol India 2012;62(2):168-71.

[11] WHO recommendations for prevention and treatment of pre-eclampsia and eclampsia. May 04, 2015. https://www.nhp.gov.in

[12] Hiralal K, Chakraborty AB. Maternal mortality: a FOGSI Study (Based on Institutional Data). JOGI 2013;63(2):88-95. 